\title{
Possible Applications of Nucleotidases in B-Chronic Lymphocytic Leukemia Patients; Egyptian Single Centre Study
}

\section{Authors
Youssef SR ${ }^{1}$, Farweez BA ${ }^{1}$, Salah Al-din YM', Ayoub MS $^{2}$}

Professor/ Soha Raouf Youssef; MD

Doctor/ Botheina Ahmed Thabet Farweez; MD

Yasmine Magdy Salah Al-din; Msc

Professor/ Maryse Soliman Ayoub; MD

${ }^{1}$ Clinical Pathology Dept, Hematology Unit, Faculty of Medicine, Ain Shams University, Cairo, Egypt

${ }^{2}$ Internal Medicine Dept, Clinical Hematology Unit, Faculty of Medicine, Ain Shams University,

Cairo, Egypt

Corresponding Author

Botheina Ahmed Thabet Farweez MD

Department of Clinical Pathology, Hematology Unit, Faculty of Medicine, Ain Shams University, Egypt Telephone: +201224563994

Email:dr_botheina@hotmail.com

\begin{abstract}
The high variability of chronic lymphocytic leukemia's (CLL) clinical presentation and disease course has been linked to availability of extracellular nucleotides and nucleosides under control of enzymes as CD39 and CD73. In this work we aimed to study the relation of CD39 and CD73 expression by B-CLL cells to the patients' clinical condition and disease outcome, aiming to apply them in routine clinical practice. The study included 40 newly diagnosed CLL patients and 20 controls. Quantification of CD73 and CD39 expression by CD19 positive cells was determined by flowcytometric analysis. A statistically significant lower percentage of lymphocytes expressing CD73 and higher ratio of CD39/CD73 in patients compared to controls were found. The percentage of cells expressing CD39 was higher in patients with lower tumor load, having a stable disease course and lymphocyte doubling time (LDT) >6 months. A cutoff point of $<19 \%$ for CD73 expression, >2 for CD39/CD73ratio confirmed the diagnosis of CLL and a cutoff point > 41\% for CD39 expression predicted clinically beneficial response to treatment. Thus, it is applicable to incorporate the detection of CD73 expression and the CD39/CD73 ratio into the CLL routine diagnostic panel and the use of CD39 as a prognostic marker for CLL.

Key Words: Nucleotidases; B-CLL; CD73; CD39; ATP; Prognostic Factor; Diagnostic Factor
\end{abstract}

\section{INTRODUCTION}

Chronic lymphocytic leukemia (CLL), the most common leukemia in adults, is a lymph proliferative disorder (LPD) with a highly variable clinical course. CLL cells depend on their microenvironment for proliferation and survival.
Extracellular nucleotides and nucleosides such as adenosine tri phosphate (ATP) and adenosine (ADO) respectively, may participate in creating favorable conditions that promote tumor growth and survival. ${ }^{[1]}$

CD39 is a prototype member of the ecto- 
nucleoside triphosphate diphosphohydrolase (NTP Dase) family. It is a cell surface enzyme expressed on endothelial cells, normal lymphocytes and other leukocytes. ${ }^{[2]}$ It hydrolyzes extracellular nucleoside diphosphates (ADP) and triphosphates (ATP) in the presence of divalent cations. ${ }^{[3]}$

CD73 is a glycophosphatidylinositol (GPI)anchored dimeric ecto-5'-nucleotidase. It is a cell surface enzyme expressed on subsets of lymphocytes, macrophages, dendritic cells, endothelial cells and epithelial cells. CD73 has important regulatory functions in the extracellular metabolism of certain nucleoside monophosphates, in particular adenosine monophosphate (AMP), it catalyses the dephosphorylation of adenosine monophosphate (AMP) to adenosine (ADO) by its soluble or membrane bound form. Thus, CD39 hydrolyzes ATP and ADP into AMP which is in turn, rapidly degraded to nucleosides, (e.g. adenosine) by CD73 which regulates the availability of adenosine for interaction with cell surface adenosine receptor. ${ }^{[4]}$

Interestingly, cancer cells express both CD39 and CD73 and extracellular adenosine produced through the activity of these enzymes on tumor cells can sufficiently down regulate antitumor immunity. ${ }^{[5]}$

Consequently we aimed to investigate the surface expression of CD39 and CD73 and their clinical significance among a group of Egyptian CLL patients.

\section{SUBJECTS AND METHODS \\ Subjects:}

This study included forty newly diagnosed adult CLL patients admitted to and followed up at the Clinical Hematology Oncology Unit, Ain Shams University hospitals in the period from January 2012 to February 2014. Patients' diagnosis, management and follow up were performed according to the 2008 International workshop on CLL update of 1996 National Cancer Institute guidelines. ${ }^{[6,7]}$ All enrolled patients had symptomatic andlor active disease necessitating therapy.

Twenty healthy age and sex matched subjects were included as a control group. The study was conducted in accordance with the stipulations of the local ethical and scientific committees of Ain shams University and was in accordance with the Helsinki Declaration of 1975.

\section{Treatment protocols:}

Patients were treated with one of the following regimens:

(1) FC- FC/R:

Fludarabine plus cyclophosphamide \pm Rituximab repeated for up to six cycles.

(2) COP- COP/R:

vincristine, cyclophosphamide and, prednisone \pm Rituximab repeated for up to eight cycles.

(3) Daily oral chlorambucil:

chlorambucil for 3- 6 weeks or more according to clinical situation.

\section{Patients' follow up:}

The elapsed time between diagnosis and treatment initiation ranged from 0 to 3 months. Restaging was performed at 3 months intervals.

The patients were followed up after 1 year from start of therapy to assess response to treatment.

\section{Study design:}

All subjects underwent the following:

1-Full clinical history taking and thorough physical examination.

2-Routine laboratory investigations including complete blood picture using (Coulter LH 750 analyzer, Beckman Coulter, CA, USA) with manual rechecking for differential leucocyte count, biochemical profile using Synchron CX7 (Beckman, Switzerland) (particularly uric acid and LDH in CLL patients) and viral markers (HBs Ag, HCV ab, HIV ab).

3- Only CLL patients underwent:

a- Bone marrow examination with examination of Leishman-stained smears and full myelogram.

b- Routine flowcytometry (FCM) immunophenotyping for LPD including at least CD5, CD19, CD23, CD20, sIg, FMC7 and CD38 labeled with either fluorescin isothiocyanate (FITC) or 
phycoerythrin (PE). Samples were considered positive for a marker if $\geq 20 \%$ of cells expressed that marker and the scoring system was applied. ${ }^{[8]}$

4- Flowcytometric assessment of CD73 and CD39 expression:

Peripheral blood samples from patients and controls were analyzed within 24 hours from collection. For each sample analyzed, an isotype matched controls was used to exclude non specific staining. Leucocyte count was adjusted to the count of 5 and $10 \times 10^{3}$ cells/ $\mu \mathrm{L}$ for optimal staining.

Sample staining:

1. $50 \mu \mathrm{L}$ of prepared sample containing at least $5 \times 10^{3}$ cells were added to each sample tube.

2. $5 \mu \mathrm{L}$ of each PE-conjugated anti-CD73 monoclonal antibody and FITC conjugated antiCD39 monoclonal antibody, PC5 conjugated antiCD19 and PC7 conjugated anti-CD5 (R\&D systems, UK) were added to each sample tube for cell staining.

3. Tubes were incubated for 15 to 20 minutes at room temperature and protected from light. 1-2ml of ammonium chloride-based erythrocyte lysing solution $(0.83 \%)$ were added to every tube and incubated for 5-10 minutes. Tubes were vortexed then washed with PBS (pH $7.2+/-0.2$ ). Cells were suspended in $0.5 \mathrm{ml}$ PBS and analyzed using Navios flowcytometer (Coulter electronics, USA).

Data interpretation:

Analysis was performed using Navios software where 10,000 events were analyzed per case or control. A flowcytometric assay protocol was constructed in which CD19/ CD5 positive lymphocytes (for patients' samples) and CD19 positive/ CD5 negative lymphocytes (for controls' samples) were selectively gated. Then, the expression of each of CD39 and CD73 as well as their co-expression was quantified in terms of percentage of expressing cells from the dual histogram. CD39/CD73 ratio was calculated by dividing the percentage of expression of CD39 over the percentage of expression of CD73.

\section{STATISTICAL ANALYSIS}

Statistical analysis was performed using SPSS V17.

Quantitative data is represented as mean with standard deviation (SD) in parametric data and as median with inter quartile range (IQR) in non parametric data.

Qualitative data is represented as number and percentage.

Comparisons of quantitative variables are conducted between groups using the student-t test for parametric data and Mann-Whitney test for non parametric data.

Comparisons between groups with parametric distribution are done by using Analysis of Variance (ANOVA) and Kruskal-Wallis for non parametric distributions.

Correlations between quantitative variables within groups are performed using the Spearman correlation coefficient.

A probability $<0.05$ is statistically significant and $<0.001$ is statistically highly significant.

A receiver operator characteristic (ROC) curve is constructed to establish clinically relevant cut off values for studied parameters with calculation of sensitivity, specificity, positive predictive value (PPV), negative predictive value (NPV) and diagnostic (or prognostic) accuracy.

\section{RESULTS:}

\section{Descriptive analyses:}

The patients' group ages ranged from 35 to 77 years with a mean age of 58.6 years. They were 29 males and 11 females with a male to female ratio of 2.6:1. While the controls' group ages ranged from 43 to 70 years with a mean age of 57.1 years. They were 14 males and 6 females with a male to female ratio of 2.3:1.

Patients were classified according to Binet clinical staging ${ }^{[7]}$, lymphocyte doubling time (LDT) ${ }^{[7]}$ and course of the disease ${ }^{[7,9]}$. Also, patients were divided into 3 groups according to tumor load (TL). Group 1 (mild TL) had a lymphocyte count below $20.0 \times 10^{9} / \mathrm{L}$ and spleen less than $5 \mathrm{~cm}$ below the costal margin. Group 2 (moderate TL) had 
fewer than $50.0 \times 10^{9} / \mathrm{L}$ lymphocytes with no limitation for spleen size. Group 3 (high TL) had no limitations for lymphocyte count or spleen size. ${ }^{[10]}$ After 1 year of follow up patients were classified according to response to treatment into clinically beneficial response group (those with partial or complete remission) and treatment failure group (those with stable disease, non response, progressive disease or death from any cause). ${ }^{[7]}$ (Table1).

CD73 was positive in 2/40 of patients (5\%) and $15 / 20$ of controls $(75 \%)$. CD39 was positive in $36 / 40$ of patients $(90 \%)$ and $19 / 20$ of controls (95\%). CD73, CD39 expression as percentage expression of cells, their co expression and their ratio in patients and controls are shown in (Table2).

\section{Comparative analyses:}

\section{1-Comparison between patients and controls:}

There was a statistically significant lower mean percentage of cells expressing CD73, coexpressing CD73 CD39 with higher ratio of CD39/CD73 expression $(\mathrm{t}=9.126, \mathrm{t}=6.997, \mathrm{z}=$ 5.489 respectively with $\mathrm{P}$-value $<0.001$ for all) in patients compared to controls, while the higher mean percentage of cells expressing CD39 in the patients compared to controls was not statistically significant $(\mathrm{t}=1.414, \mathrm{P}=0.163)$ (Figure1).

\section{2-Comparisons between patients' subgroups: CD73 expression:}

There was no significant difference found between patients subgroups as regards CD73 expression ( $\mathrm{p}>0.05$ for all) (Table 3 ).

\section{CD39 expression:}

There was a higher mean percentage of CD39 ${ }^{+}$ lymphocytes in patients with low tumor load compared to high tumor load $(\mathrm{p}=0.025)$, in cases with long LDT $\geq 6 \mathrm{~m}$ compared to short LDT < $6 \mathrm{~m}(\mathrm{p}=0.005)$ and in cases with stable disease compared to progressive disease but the difference was of borderline significance $(\mathrm{P}=0.05)$. Percentage of $\mathrm{CD} 39^{+}$lymphocytes was higher in clinically beneficial response than treatment failure patients but the difference was not statistically significant (Table 3).

\section{CD73 and CD39 co-expression:}

There was a statistically significant higher mean percentage of CD39 CD73co-expression in clinically beneficial response patients $(p=0.028)$ while the results were comparable between other patients' subgroups (Table 3).

\section{CD39: CD73 ratio:}

There was a statistically significant lower median CD39/ CD73 ratio in patients with LDT $\leq 6 \mathrm{~m}$ $(\mathrm{p}=0.038)$, while the results were comparable between other patients' subgroups (Table 3 ).

\section{Correlation studies: CD73 expression:}

There was a significant positive correlation between CD73 and CD23 expression $(r=0.423$ $\mathrm{p}=0.007$ ).

\section{CD39 expression:}

There was a significant negative correlation between CD39 expression and white blood cell (WBC) count, percent of bone marrow lymphocytes, expression of CD19 and CD79b ( $\mathrm{r}=-$ $0.400 \mathrm{p}=0.010, \quad \mathrm{r}=-0.403 \mathrm{p}=0.010, \mathrm{r}=-0.325$ $\mathrm{p}=0.049, \mathrm{r}=-0.325 \mathrm{p}=0.041$ respectively).

Performance characteristics of CD73 and CD39 expression:

Using the Receiver Operator Characteristics (ROC) curve analysis

\section{Diagnostic performance:}

A cutoff point of $\leq 19 \%$ for $\mathrm{CD}^{+} 3^{+}$cells, $>50 \%$ for $\mathrm{CD} 9^{+}$cells, $\geq 2.0$ for $\mathrm{CD} 39 / \mathrm{CD} 73$ ratio and $\leq 11 \%$ for CD39 CD73 co-expression in CLL patients yielded a diagnostic accuracy of (96\%, $62 \%, 93.7 \%$ and $92.6 \%$ respectively) (Figure 2).

\section{Prognostic performance:}

A cutoff point of $>41 \%$ for $\mathrm{CD} 39^{+}$cells, $>12 \%$ for $\mathrm{CD} 73^{+}$cells, $\leq 4.063$ for $\mathrm{CD} 39 / \mathrm{CD} 73$ ratio and $>5.4 \%$ for CD39 CD73 co-expression in CLL patients yielded a prognostic accuracy for predicting clinically beneficial response to treatment of $(72 \%, 71.8 \%, 55.9 \%$ and $72.5 \%$ respectively) (Figure 3).

\section{DISCUSSION}

CLL cells show markedly distinct behaviors in the blood or in the lymph nodes, with proliferation 
occurring almost exclusively in the latter. These observations suggest that local microenvironments provide elements and conditions supporting growth, diffusion, and resistance to therapy. ${ }^{[5]}$

Among the pathological alterations that give tumor cells invasive potential, purinergic signaling is emerging as an important component. Extracellular ATP and adenosine have been shown to mediate a variety of biological functions, including events related to cell proliferation, cell differentiation and cell death. The effects of nucleotides and nucleosides on purinergic receptors are regulated by the action of CD39 and CD73. ${ }^{[11]}$

This study aimed to analyze level of expression of CD39 and CD73 by B cells in CLL patients and their relationship to the patients' clinical condition, disease prognostic parameters and patients' outcome. Current results showed a statistically significant lower mean percentage of lymphocytes positive for CD73 among CLL patients compared to healthy controls. Similar results were obtained by Rosi and colleagues in $2002^{[12]}$ in which the percentage of CD73 positive cells in $\mathrm{CD}_{1} 9^{+} \mathrm{CD}^{+}$populations was reduced at least by $95 \%$ in CLL lymphocytes compared to controls and likely, Serra and colleagues in $2011^{[5]}$ observed that $60 \%$ of their study group had less than $10 \%$ of $\mathrm{CD} 19^{+} / \mathrm{CD} 73^{+}$cells in the peripheral blood.

Also, Pulte and colleagues in $2011^{[13]}$ showed that CD73 expression on malignant B lymphocytes was generally lower compared with normal B lymphocytes (19.3\% overall for CLL vs. $77 \%$ in normal B cells). However some of their patients, like ours, had very high expression of CD73 on the malignant clone, suggesting that most CLL clones are $\mathrm{CD} 73^{-}$but a minority of patients may have $\mathrm{CD}^{+} 3^{+} \mathrm{CLL}$ clones. They identified 2 subtypes of CLL cases based on their CD73 expression. They found most of the patients with $\mathrm{CD}^{+} 3^{+}$clones to be Rai stage I (Early disease stage). In our study, due to the late presentation of most Egyptian CLL patients most of our patients presented in later stage disease (Binet stage B and
C). This difference in patients' distribution may explain the fewer $\mathrm{CD}^{+} 3^{+}$cases $(5 \%)$ encountered in the study.

A cut-off value of $<19 \%$ for CD73 expression was able to discriminate between CLL patients and healthy controls with $96 \%$ diagnostic accuracy. This finding supports the incorporation of surface expression of $\mathrm{CD} 73$ in the routine initial diagnostic workup of CLL with almost the same cutoff for positivity (about 20\%) as other markers used and encourages its study in different LPD.

As regards CD39 expression, it showed no significant difference in percentage of lymphocytes positive for CD39 among CLL patients compared to healthy controls. Similarly, Pulte and colleagues in $2007^{[2]}$ found that CLL cells had equal to or slightly lower level of expression of CD39 than that of normal Blymphocytes when all cases of CLL were considered together.

CD39 expression was evaluated after classifying patients according to the course of disease where a lower mean percentage of CD39 positive lymphocytes were found in patients with aggressive course compared to patients with stable course however this was of borderline statistical significance. Pulte and colleagues in $2007^{[2]}$ found that lower levels of CD39 were associated with younger age, progression of disease, and advanced stage of the disorder and when they compared CD39 expressed on normal B lymphocytes and CLL cells, they observed that lymphocytes from Rai stage 0-2 CLL showed mildly increased activity while lymphocytes from Rai stage 3-4 CLL showed decreased activity. They concluded that CD39 may be a marker of less aggressive disease and a drop in CD39 expression may be indicative of progression of the disease. They hypothesized that sensitivity to apoptosis is decreased in cells with lower CD39 levels which would explain the aggressive course. Our correlation studies showed that percentage of lymphocytes positive for CD39 expression were negatively correlated with higher WBC count, higher percentage of BM lymphocytes, and higher 
percentage of cells positive for CD19 and CD79b. It could be explained by the fact that high WBCs count and percentage of BM lymphocytes are commonly interpreted as indicators of high tumor burden or tumor aggressiveness, thus conferring a poor prognosis and correlating with disease stage in patients with CLL.

A cutoff point of $>41 \%$ CD39 positive cells was able to predict clinically beneficial response to treatment with $100 \%$ sensitivity and $72 \%$ prognostic accuracy. Thus, with respect to the clinical relevance of CD39 expression by B-cells it was evident from these findings that the loss of its expression was an indicator of progressive disease, high tumor load and treatment failure.

There was a significantly higher percentage of lymphocytes co-expressing both CD39 and CD73in patients achieving clinically beneficial response to treatment. Based on earlier findings with respect to CD39 this is attributed to higher CD39 expression in clinically beneficial response patients. In contrast, patients with LDT $<6 \mathrm{~m}$ had a significantly lower CD39/CD73 ratio compared to those with LDT $>6 \mathrm{~m}$ which was due to markedly lower CD39 expression in patients with shorter LDT.

In this study we explored the relation of CD73 and CD39 expression to the development and progression of CLL. The following summarizes our results: CD73 is very weakly expressed in most CLL patients compared to the controls. In addition it had a statistically significant diagnostic cutoff of about $20 \%$ making it amenable to use in routine diagnostic immunophenotyping workup. Also, CD39/CD73 ratio proved to have a better diagnostic than prognostic accuracy. CD39 was found to be variably expressed in CLL patients with the loss of its expression being an indicator of aggressive disease, high tumor load and treatment failure. CD39 was also found to be an independent prognostic marker for CLL with a cutoff of about $40 \%$.
Table (1): Patients' clinical subgroups

\begin{tabular}{|c|c|c|}
\hline Parameter & Finding & $\mathbf{N}(\%)$ \\
\hline \multirow{3}{*}{$\begin{array}{l}\text { Binet clinical } \\
\text { staging }\end{array}$} & $\begin{array}{l}\text { A } \\
(25 \%)\end{array}$ & 10 \\
\hline & $\begin{array}{l}\mathrm{B} \\
(35 \%)\end{array}$ & 14 \\
\hline & $\begin{array}{l}\mathrm{C} \\
(40 \%) \\
\end{array}$ & 16 \\
\hline \multirow[t]{2}{*}{ Course of disease } & $\begin{array}{l}\text { Progressive } \\
(55 \%)\end{array}$ & 22 \\
\hline & $\begin{array}{l}\text { Stable } \\
(45 \%)\end{array}$ & 18 \\
\hline \multirow{2}{*}{$\begin{array}{ll}\text { Response } & \text { to } \\
\text { treatment }\end{array}$} & Clinically beneficial respons & $6(15 \%)$ \\
\hline & $\begin{array}{l}\text { Treatment failure } \\
(85 \%)\end{array}$ & 34 \\
\hline \multirow[t]{3}{*}{ Tumor load } & $\begin{array}{l}\text { Low } \\
(37.5 \%)\end{array}$ & 15 \\
\hline & $\begin{array}{l}\text { Moderate } \\
(32.5 \%)\end{array}$ & 13 \\
\hline & $\begin{array}{l}\text { High } \\
(30 \%)\end{array}$ & 12 \\
\hline \multirow[t]{2}{*}{$\begin{array}{l}\text { Lymphocyte } \\
\text { doubling time }\end{array}$} & $\begin{array}{l}<6 \text { months } \\
(50 \%)\end{array}$ & 20 \\
\hline & $\begin{array}{l}>6 \text { months } \\
(50 \%)\end{array}$ & 20 \\
\hline
\end{tabular}

N: number of patients

Table (2):Quantitative data of patients and controls as regards flowcytometric expression CD73, CD39, Co-expression of CD73 CD39 and their ratio.

\begin{tabular}{||l||l|l||}
\hline \hline \multirow{2}{*}{ Parameter } & GROUPS & Controls \\
\cline { 2 - 3 } & Patient & $41.250 \pm: 15.269$ \\
\hline $\begin{array}{l}\text { CD 73 } \\
\text { Mean } \pm \text { SD }\end{array}$ & $11.330 \pm 9.979$ & $38.750 \pm: 11.603$ \\
\hline $\begin{array}{l}\text { CD 39 } \\
\text { Mean } \pm \text { SD }\end{array}$ & $46.873 \pm 24.257$ & $17.585 \pm: 7.461$ \\
$\begin{array}{l}\text { Co-expression of } \\
\text { CD 39 \&CD73 } \\
\text { Mean } \pm \text { SD }\end{array}$ & $6.305 \quad \pm 4.941$ & $1.095(0.753)$ \\
$\begin{array}{l}\text { Ratio CD39/CD73 } \\
\text { median(IQR) }\end{array}$ & $5.00(5.949)$ & \\
\hline
\end{tabular}


Table (3):Comparison between patients' clinical groups as regards flowcytometric expression CD73, CD39, Co-expression of CD73 CD39 and their ratio.

\begin{tabular}{|c|c|c|c|c|c|}
\hline \multicolumn{2}{|c|}{ Patients' groups } & $\begin{array}{l}\text { CD73 } \\
\text { expression }(\%) \\
(\text { mean } \pm \text { SD })\end{array}$ & $\begin{array}{l}\text { CD39 } \\
\text { expression }(\%) \\
(\text { mean } \pm \text { SD) }\end{array}$ & $\begin{array}{l}\text { Co-expression } \\
\text { CD73CD39 } \\
(\%) \\
(\text { mean } \pm \text { SD }) \\
\end{array}$ & $\begin{array}{l}\text { CD39/73 } \\
\text { Ratio } \\
\text { median (IQR) }\end{array}$ \\
\hline \multirow{3}{*}{$\begin{array}{l}\text { Course of } \\
\text { disease }\end{array}$} & Stable & $11.3 \pm 6.1$ & $54.8 \pm 17.8$ & $7.1 \pm 5.4$ & $5.308(5.502)$ \\
\hline & progressive & $11.3 \pm 12.4$ & $40.3 \pm 27.1$ & $5.6 \pm 4.5$ & $4.875(6.670)$ \\
\hline & $\begin{array}{l}\text { P value } \\
(\mathrm{t} / \mathrm{z})\end{array}$ & $\begin{array}{l}0.999 \\
(0.001)\end{array}$ & $\begin{array}{l}0.059^{*} \\
(-1.943)\end{array}$ & $\begin{array}{l}0.358 \\
(-0.931)\end{array}$ & $\begin{array}{l}0.471 \\
(-0.721)\end{array}$ \\
\hline \multirow[t]{3}{*}{ LDT } & $<6$ month & $12.2 \pm 12.9$ & $36.3 \pm 24.2$ & $5.5 \pm 4.7$ & $3.766(4.909)$ \\
\hline & $>6$ months & $10.4 \pm 5.9$ & $57.3 \pm 19.7$ & $7.0 \pm 5.1$ & $6.056(5.595)$ \\
\hline & $\begin{array}{l}\text { P value } \\
(\mathrm{t} / \mathrm{z})\end{array}$ & $\begin{array}{l}0.569 \\
(0.575) \\
\end{array}$ & $\begin{array}{l}0.005^{*} \\
(-2.999) \\
\end{array}$ & $\begin{array}{l}0.341 \\
(-0.965) \\
\end{array}$ & $\begin{array}{l}0.038^{*} \\
(-2.070) \\
\end{array}$ \\
\hline \multirow{4}{*}{$\begin{array}{l}\text { Tumor } \\
\text { load }\end{array}$} & Low & $11.1 \pm 6.6$ & $56.5 \pm 17.2$ & $7.6 \pm 5.5$ & $6.444(4.604)$ \\
\hline & Moderate & $9.562 \pm 4.48$ & $49.45 \pm 25.94$ & $5.94 \pm 4.27$ & $5.083(3.963)$ \\
\hline & High & $13.4 \pm 16.3$ & $32.0 \pm 24.3$ & $5.0 \pm 4.8$ & $2.691(7.547$ \\
\hline & $\begin{array}{l}\text { P value } \\
(\text { F/z) }\end{array}$ & $\begin{array}{l}0.625 \\
(0.476)\end{array}$ & $\begin{array}{l}0.025^{*} \\
(4.073)\end{array}$ & $\begin{array}{l}0.410 \\
(0.913)\end{array}$ & $\begin{array}{l}0.278 \\
(2.558)\end{array}$ \\
\hline \multirow[t]{3}{*}{$\begin{array}{l}\text { Response } \\
\text { to } \\
\text { treatment }\end{array}$} & $\begin{array}{l}\text { Clinically } \\
\text { beneficial } \\
\text { response }\end{array}$ & $15.1 \pm 7.1$ & $62.0 \pm 12.2$ & $10.3 \pm 6.5$ & $3.531(7.434)$ \\
\hline & $\begin{array}{l}\text { Treatment } \\
\text { failure }\end{array}$ & $10.6 \pm 10.3$ & $44.2 \pm 24.9$ & $5.5 \pm 4.3$ & $5.042(5.906)$ \\
\hline & $\begin{array}{l}\text { P value } \\
(\mathrm{t} / \mathrm{z})\end{array}$ & $\begin{array}{l}0.313 \\
(-1.022) \\
\end{array}$ & $\begin{array}{l}0.098 \\
(-1.696)\end{array}$ & $\begin{array}{l}0.028^{*} \\
(-2.290) \\
\end{array}$ & $\begin{array}{l}0.649 \\
(-0.455) \\
\end{array}$ \\
\hline \multirow{4}{*}{$\begin{array}{l}\text { Binet } \\
\text { clinical } \\
\text { staging }\end{array}$} & Stage A & $13.2+6.1$ & $56.3 \pm 18.9$ & $8.4 \pm 5.7$ & $4.110(4.986)$ \\
\hline & Stage B & $7.3 \pm 3.5$ & $47.3 \pm 27.6$ & $4.2 \pm 2.8$ & $5.722(8.500)$ \\
\hline & Stage C & $12.1 \pm 14.2$ & $38.2 \pm 24.4$ & $5.7 \pm 4.7$ & $4.917(7.842)$ \\
\hline & $\begin{array}{l}\text { P value } \\
\text { (F/z) }\end{array}$ & $\begin{array}{l}0.34 \\
(1.106) \\
\end{array}$ & $\begin{array}{l}0.12 \\
(2.213) \\
\end{array}$ & $\begin{array}{l}0.10 \\
(2.444) \\
\end{array}$ & $\begin{array}{l}0.49 \\
(1.411) \\
\end{array}$ \\
\hline
\end{tabular}

*= significant value, $\mathrm{IQR}=$ interquartile range, $\mathrm{SD}=$ standard deviation

\section{Captions to illustrations:}

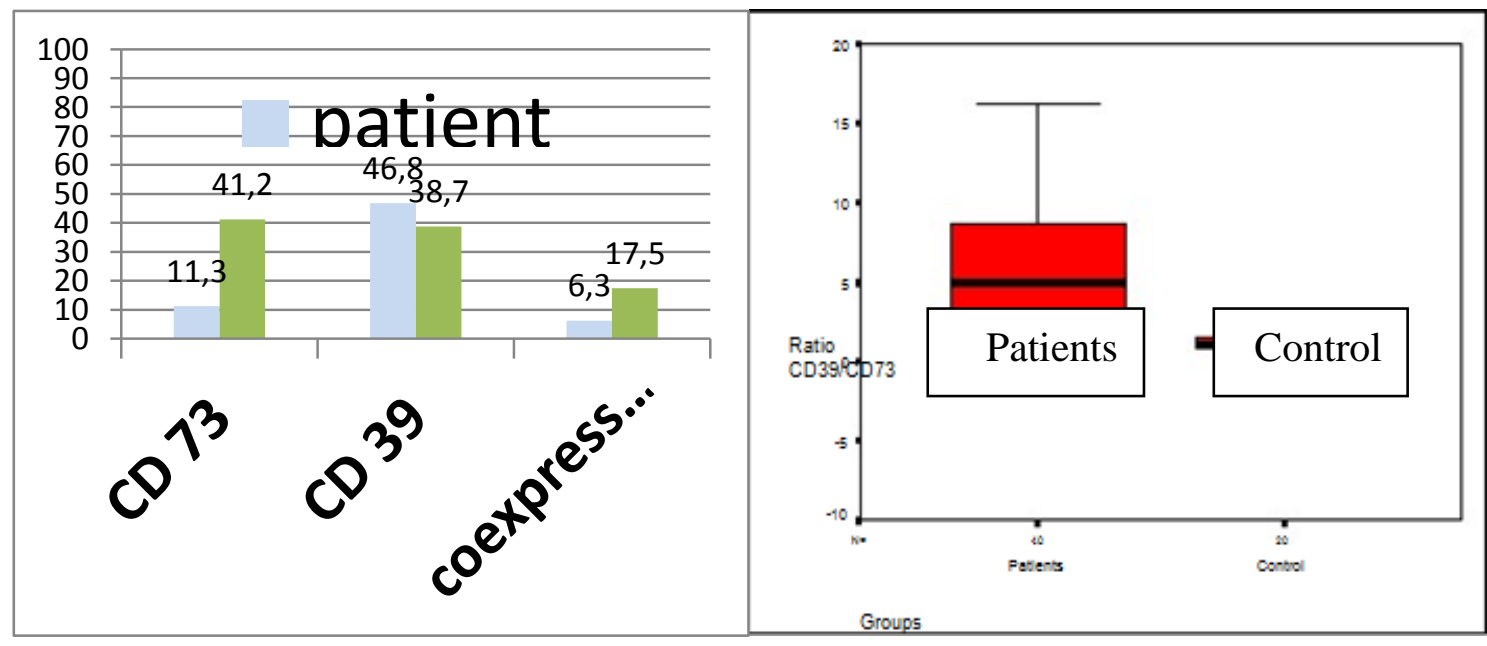

Figure (1): Comparison between patients and controls as regards mean percentage of cells expressing CD73, CD39, co-expressing CD73 and CD39 and median value of CD39/CD73 Ratio. 


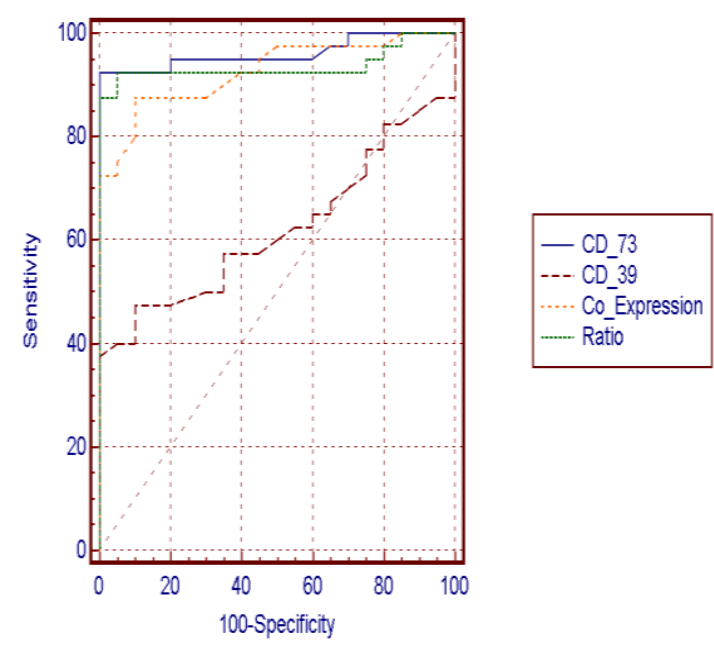

\begin{tabular}{|l|l|l|l|l|l|l|}
\hline \hline Parameter & Cutoff & Sensitivity & Specificity & PPV & NPV & Accuracy \\
\hline CD73 & $<19$ & 92.5 & 100.0 & 100.0 & 87.0 & 0.962 \\
\hline CD39 & $>50$ & 47.5 & 90.0 & 90.5 & 46.2 & 0.621 \\
\hline $\begin{array}{l}\text { Ratio 39/73 } \\
\text { Co- } \\
\text { expression }\end{array}$ & $<11$ & 92.5 & 95.0 & 97.4 & 86.4 & 0.937 \\
\hline
\end{tabular}

$\mathrm{PPV}=$ positive predictive value; $\mathrm{NPV}=$ negative predictive value

Figure (2): ROC curve showing CD73, CD39, their co-expression and the ratio between them as regards their performance as diagnostic markers of CLL.

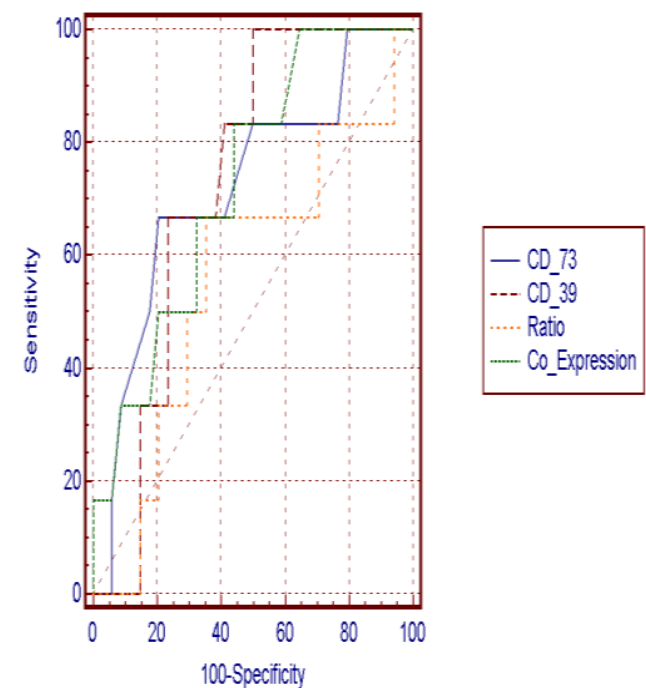

\begin{tabular}{|l|l|l|l|l|l|l|}
\hline Parameter & Cutoff & Sensitivity & Specificity & PPV & NPV & Accuracy \\
\hline CD73 & $>12$ & 66.7 & 79.4 & 36.4 & 93.1 & 0.718 \\
\hline CD39 & $>41$ & 100.0 & 50.0 & 26.1 & 100.0 & 0.723 \\
\hline $\begin{array}{l}\text { Ratio } \\
\text { CD39/CD73 }\end{array}$ & $<4.063$ & 66.7 & 64.7 & 25.0 & 91.7 & 0.559 \\
\hline \hline Co-expression & $>5.4$ & 83.3 & 55.9 & 25.0 & 95.0 & 0.725 \\
\hline
\end{tabular}

$\mathrm{PPV}=$ positive predictive value; $\mathrm{NPV}=$ negative predictive value

Figure (3): ROC curve showing CD73, CD39, their co-expression and the ratio between them as regards their performance as prognostic markers for treatment response in CLL.

\section{Conflict of interest:}

The authors declare that they have no potential conflicts of interest.

\section{REFRENCES}

1. Catovsky D and Montserrat E. Chronic lymphocytic leukaemia and other B-cell disorders. In: Postgraduate haematology .By: Hoffbrand A, Catovsky D, Tuddenham E and Anthony R (eds), Blackwell Publishing, $6^{\text {th }}$ edition 2011; 3:530-74.

2. Pulte D, Olson KE, Broekman MJ, Islam $\mathrm{N}$, Ballard HS, Furman RR, Olson AE and
Marcus AJ. CD39 activity correlates with stage and with platelets reactivity in chronic lymphocytic leukemia. J.Transl. Med, 2007; 4(5): 23-9.

3. Zhong X, Buddha M, Guidotti G, Kriz R, Somers W and Mosyak L. Expression, purification and crystallization of the ectoenzymatic domain of rat E-NTPDase1 CD39. Acta Crystallogr Sect F Struct Biol Cryst Commun., 2008; 64(Pt 11):1063-5.

4. Heuts DP, Weissenborn MJ, Olkhov RV, Shaw AM, Gummadova J, Levy $\mathrm{C}$ and Scrutton NS. Crystal structure of a soluble form of human CD73 with ecto 
5'nucleotidase activity. Chembiochem. 2012; 13(16):2384-91.

5. Serra S, Horenstein AL, Vaisitti T, Brusa D, Rossi D, Laurenti L, D'Arena G, Coscia M, Tripodo $\quad \mathrm{C}$, Inghirami G, Robson SC, Gaidano G, Malavasi F and Deaglio S.CD73-generated extracellular adenosine in chronic lymphocytic leukemia creates local conditions counteracting druginduced cell death. Blood, 2011; 118(23): 6141-52.

6. Muller-Hermelink H, Montserrat E, Catovsky D, Campo E, Harris N and Stein H. Chronic lymphocytic leukemia/small lymphocytic lymphoma. In: WHO Classification of Tumors of Haematopoietic and lymphoid Tissues. By: Swerdlow S, Campo E, Harris N, Jaffe E, Pileri S, Stein H, Thieele $\mathrm{J}$ and Vardiman J(eds). IARC, $4^{\text {th }}$ edition 2008; 2:180-2.

7. Hallek M, Cheson B, Catovsky D, Caligaris-Cappio F, Dighiero G, Döhner $\mathrm{H}$, Hillmen P, Keating M, Montserrat E, Rai $\mathrm{K}$ and Kipps T. Guidelines for the diagnosis and treatment of chronic lymphocytic leukemia: a report from the International Workshop on Chronic Lymphocytic Leukemia updating the National Cancer Institute-Working Group 1996 guidelines. Blood 2008; 111(12): 5446-56.

8. Matutes E, Owusu-Ankomah K, Morilla R, Garcia Marco J, Houlihan A, Que TH and Catovsky D. The immunological profile of B-cell disorders and proposal of a scoring system for the diagnosis of CLL. Leukemia, 1994;8 (10):1640-5.

9. Eichhorst B and Hallek M. Revision of the guidelines for diagnosis and therapy of chronic lymphocytic leukemia (CLL). Best Practice \& Research Clinical Haematology; 2007; 20(3):469-77.
10. Huhn D, Von Schilling C, Wilhelm M, Ho A, Hallek M, Kuse R, Knauf W, Riedel U, Hinke A, Srock S, Serke S, Peschel C, Emmerich B for the German Chronic Lymphocytic Leukemia Study Group. Rituximab therapy of patients with B-cell chronic lymphocytic leukemia. Blood, 2001; 98(5):1326-31.

11. Cappellari AR, Vasques GJ, Bavaresco L, Braganhol $\mathrm{E}$ and Battastini AM. Involvement of ecto-5'nucleotidase/CD73 in U138MG glioma cell adhesion. Mol Cell Biochem., 2012; 359(1-2):315-22.

12. Rosi F, Carlucci F, Marinello E and Tabucchi E. Ecto-5'-nucleotidase in B-cell chronic lymphocytic leukemia. Biomed Pharmacother; 2002, 56:100-4.

13. Pulte D, Furman RR, Olson KE, Ballard HS and Marcus AJ. CD39 expression on T cells correlates with severity of diseases in patients with chronic lymphocytic leukemia. Lymphoma Myeloma leuk.,2011; 11(4):367-72. 